\title{
Highly Ordered Hybrid Mesoporous Organosilica: An Exceptional Anchor for Pd Nanoparticles and Catalyst Nitroaromatic Reduction
}

\section{Ali Zebardasti}

Iran University of Science and Technology

Mohammad G. Dekamin ( $\sim$ mdekamin@iust.ac.ir)

Iran University of Science and Technology

\section{Esmail Doustkhah}

International Center for Materials Nanoarchitechtonics (MANA), National Institute for Materials Science (NIMS), 1-1 Namiki, Tsukuba, Ibaraki 305-0044

\section{Research Article}

Keywords: Hybrid mesoporous organosilica, Pd nanoparticles, p-nitrophenol, reduction, heterogeneous catalyst, Green chemistry.

Posted Date: January 28th, 2021

DOI: https://doi.org/10.21203/rs.3.rs-153162/v1

License: (c) (i) This work is licensed under a Creative Commons Attribution 4.0 International License. Read Full License 


\section{Abstract}

Hybridization of mesoporous organosilica (MO) to reinforce the surface capability in adsorption and stabilization of noble metal nanoparticles are of great attention in generating noble metal-based catalysts. Here, we used a unique hybrid of organic-inorganic mesoporous silica which in pore profile pattern was similar to the well-known mesoporous silica, SBA-15. This hybrid mesoporous silica was further incorporated in the synthesis and stabilization of Pd nanoparticles on its surface and then, the obtained Pd supported MO, was employed as a heterogeneous green catalyst in the conversion of $p$ nitrophenol (PNP) to $p$-aminophenol (PAP) at room temperature with efficient recyclability.

\section{Introduction}

Mesoporous silicas modified/constructed by organosiloxanes $(\mathrm{MO})^{1-4}$ are a class of hybrid silica-based materials that are widely used in the diverse applications including catalysis ${ }^{4,5}$, microextraction ${ }^{6}$, water treatment ${ }^{7}$, molecular recognition ${ }^{8}$, photocatalysis ${ }^{9}$, optical thermometry ${ }^{10}$, sensors ${ }^{11,12}, \mathrm{CO}_{2}$ capture $^{13,14}$. These materials can be synthesized by incorporating organosiloxane bridges and usually have amorphous structure but with ordered/disordered pore channels. Some of these materials can have microporosity alongside the mesoporosity which can increase the surface area and subsequently efficiency of the material in the applications ${ }^{15,16}$. Since these materials are synthetic, there should be a synthetic bottom-up strategy for the reaching to such materials in which the presence of template (mostly a soft template), e.g., F127 and P123, is inevitable ${ }^{17-19}$.

When an organosiloxane bridge with significant flexibility is being used in a MO's structure, the organosiloxane bridge should co-condense with a silica source (e.g., TEOS) to generate a uniform and robust mesoporous structure from viewpoint of mechanical toughness and porosity ${ }^{4}$. Several advantages belong to MOs, which cannot be found in conventional hybrid mesoporous silica materials ${ }^{20}$. For instance, in MOs, depending on the type of bridge, a higher ratio of organosilica can be embedded in the structure of $\mathrm{MO}$, while in the case of conventional mesopores, e.g., SBA-15, it is an overwhelming process usually deals with pore blocking or unsuccessful process ${ }^{21}$. In MOs, the pore transfer for guest molecules are more efficient and more promising than conventional hybrid silica mesopores ${ }^{22-24}$. This efficiency in molecules transfer improves the lifetime of the $\mathrm{MO}$ and catalytic activity by minimizing the pore-blocking possibility by guest molecules ${ }^{25-27}$. This is because the organosilica motif of conventional mesoporous silicas stay on the external surface of pore channels while in MOs, it can be embedded in the pore wall 28,29 .

The use of mesoporous silica materials are of great importance among the candidates for synthesis of heterogeneous catalysts ${ }^{30-32}$. These materials can provide excellent heterogeneous surface for immobilization of catalytically active metal species for various reactions, such as cross coupling and reduction reactions ${ }^{33-37}$. These materials can also provide an excelling recyclability by tuning the ratio and type of the organosilica. Pd, among the noble metals, have played a pivotal role in the catalysis since 
$\mathrm{Pd}$ is an active catalytic species for a broad domain of reactions, e.g., cross-coupling ${ }^{38}$, oxidation ${ }^{39}$, reduction 40,41 , and dehydrogenation ${ }^{42}$. Here, we integrated the isocyanurate and carbamate functional groups in the $\mathrm{MO}$ and used it for Pd nanoparticles supporting. This was further employed as a heterogeneous green catalyst for the aqueous room temperature reduction of PNP to PAP using $\mathrm{NaBH}_{4}$.

\section{Results And Discussion}

An organosilica porous material which was synthesized by co-condensation method, where the organic and inorganic are homogeneously mixed and dissolved to afford a new material in the presence of P123. Since this hybrid mesoporous silica material has been obtained by co-condensation of a synthetic organosiloxane, a facile one step solvent-free approach to synthesize the organosiloxane precursor was developed in our lab, as represented in Fig. 1.

The successful synthesis of this organosiloxane bridge using various techniques such as ${ }^{1} \mathrm{H}$ - and ${ }^{13} \mathrm{C}$ NMR, FTIR and mass spectroscopy was developed ${ }^{14}$, which all have been discussed in our previous work $^{14}$. We used this isocyanurate-carbamate organosiloxane bridge (ISO bridge) to synthesize the mesoporous organosilica (MO-ISO) with a high surface area and mechanically stable properties. Since in the previous study, we showed that the ratio of TEOS to organosiloxane precursor has a critical effect on the surface area and morphology, we selected the molar ratio of 1:15 (organosiloxane to TEOS, respectively). For studying the surface area, the $\mathrm{N}_{2}$ adsorption-desorption isotherms of the synthesized MO-ISO was evaluated and represented in Fig. 2. Accordingly, the surface area was obtained around 697 $\mathrm{m}^{2} \cdot \mathrm{g}^{-1}$ with type IV isotherm and the average pore size is $6.2 \mathrm{~nm}$. Going further, the Pd supported MO-ISO (Pd@MO-ISO) has exhibited a relative loss in the surface area $\left(389 \mathrm{~m}^{2} \cdot \mathrm{g}^{-1}\right)$, however, the surface area is still high, compared to other porous materials (Fig. 2).

The FTIR spectrum for the heterocyclic starting material of ISO bridge was compared with the FTIR spectrum of the MO-ISO to see if the main structure of ISO has undergone no change (Fig. 3). This can be judged by the existence of two sharp bands at 1467 and $1700 \mathrm{~cm}^{-1}$ related to the stretching vibrations of the isocyanurate carbonyl located in the ring. A small shift in this regard can be observed to these band positions which can be attributed to the change in the intermolecular hydrogen bondings in the pure form and when embedded in the MO structure. Some peaks in the range of $2900-3000 \mathrm{~cm}^{-1}$ are also related to the aliphatic chains (ethylene) of the ISO bridge.

Since the generated carbamate groups are sensitive to the acidic and basic media, we carefully examined appeared two peaks the ${ }^{13} \mathrm{C}$-NMR of MO-ISO related to the carbonyls (one to carbamate (156 ppm) and another to the isocyanurate (148 ppm) which can confirm that the ISO bridge has been retained intact in the structure ${ }^{14}$.

SEM micrographs of MO-THEIC morphology exhibits micro-sized particles, showing that the mesopores are assembled and aggregated into the large particles (Fig. 4A). Furthermore, high-angle annular dark- 
field scanning transmission electron microscopy (HAADF-STEM) image of MO-ISO confirms the presence of Pd nanoparticles distributed in the MO-ISO's matrix. Note that the Pd nanoparticles are with lighter color since the more condense matter, the lighter appearance it takes in HAADF-STEM image (Fig. 4B). looking at the TEM image of MO-ISO reveals that the structure of MO-ISO is the hexagonally ordered with uniform pore size distribution (Fig. 4C). Moreover, the Pd supported MO-ISO confirms the presence of Pd nanoparticles are formed on the MO-ISO (Fig. 4D). The calculated sizes of Pd nanoparticles according to the TEM image are found to be sub- $20 \mathrm{~nm}$.

Further, the Pd nanoparticles and the MO-ISO structure using elemental TEM-mapping and TEM-based electron dispersive spectroscopy (EDS) were studied. It was confirmed that the Pd nanoparticles have been supported in MO-ISO structure using scanning the related elements of $\mathrm{O}, \mathrm{N}, \mathrm{C}$, and $\mathrm{Si}$ elements by TEM-mapping (Fig. 5A). Also, Fig. 5B shows the TEM-EDS spectra of Pd@MO-ISO. This analysis confirms the presence of Pd element in the structure as well as other critical elements, e.g., C, N, and Si.

\section{Catalytic test of Pd@MO-ISO for the reduction of nitroaromatics}

Further, the catalytic activity of Pd@MO-ISO in the reduction of nitroaromatics was examined by testing PNP in the aqueous media at room temperature. In this regard, $\mathrm{NaBH}_{4}$ as reducing agent was used in $\mathrm{H}_{2} \mathrm{O}$ as the best solvent in terms of green chemistry principles. The catalyst, Pd@MO-ISO was used in different loadings to find which ratio of Pd to the reactant, PNP, has the higher TON. Accordingly, the results indicated that $5 \mathrm{mg}$ catalyst in $3 \mathrm{mM}$ PNP solution $(40 \mathrm{~mL})$ has a higher activity in terms of turnover frequency (TON). The calculated TON was found to be 513 for the PNP reduction in the presence of $5 \mathrm{mg}$ Pd@MO-ISO (with $0.5 \mathrm{wt} \%$ of Pd content) and $0.12 \mathrm{mmol}$ PNP. Indeed, higher catalyst loadings than $5 \mathrm{mg}$ do not have enough effect on the improvement of the reaction yeild from viewpoint of Pd to reactant molar ratio. Furthermore, the reduction reaction in the presence of optimal loading of Pd@MO-ISO versus the time was examined by taking a sample every 5 min to record its UV-Visible spectrum. It was realized that the major fraction of the reaction progress occurs at early $10 \mathrm{~min}$. The obtained results confirmed the conversion of PNP to PAP by fading an adsorption peak at $410 \mathrm{~nm}$ and appearing a related peak at 317 nm over the reaction time (Fig. 6).

Also, the recyclability of the Pd@MO-ISO catalyst was studied since the recyclability is one of the pivotal features for using heterogeneous catalysts in different organic transformations. Accordingly, we used the optimized reaction conditions, i.e., $3 \mathrm{mM}$ PNP, room temperature, aqueous conditions, and $5 \mathrm{mmol}$ $\mathrm{NaBH}_{4}$. The results show that Pd@MO-ISO catalyst is easily recoverable and reusable at least for five consecutive cycles (Fig. 7A). In addition, the analysis of the reaction solution, once the catalyst is filtered, through atomic absorption spectroscopy (AAS) in the fifth cycle, confirmed that the Pd leaching is negligible ( $<1 \%)$. SEM-based EDS spectra of recovered Pd@MO-ISO after five cycles also shows the presence of Pd species, further confirming the resistance of the material against Pd leaching (Fig. 7B). 
The catalytic performance of our catalyst and method with the previously reported catalytic systems was compared for PNP reduction to PAP. It is obvious that this new introduced catalyst is superior to several catalysts and methods in terms of TON (Table 1).

Table 1

Comparing the PNP reduction through our synthesized catalyst and the previously reported catalysts.

\begin{tabular}{|lclllll|}
\hline Catalyst & $t(m i n)$ & Reductant & Solvent & Temp. $\left({ }^{\circ} \mathrm{C}\right)$ & TON & Ref. \\
\hline TA@Fe ${ }_{3} \mathrm{O}_{4}$-AgNPs & 6 & $\mathrm{NaBH}_{4}$ & Water & r.t. & 25 & {$\left[{ }^{43}\right]$} \\
\hline$\left[\mathrm{PdCl}_{\mathrm{x}}(\mathrm{ACN})_{\mathrm{y}}\left(\mathrm{NH}_{2}-\mathrm{CS}\right)_{\mathrm{z}}\right]^{2-}$ & 120 & $\mathrm{NaBH}_{4}$ & Water & 22 & 10 & {$\left[{ }^{44}\right]$} \\
\hline $\mathrm{Pd@MO-Urea}$ & 26 & $\mathrm{NaBH}_{4}$ & Water & r.t. & 64 & {$\left[{ }_{4}\right]$} \\
\hline Pd@MO-ISO & 20 & $\mathrm{NaBH}_{4}$ & Water & r.t. & 513 & This work \\
\hline
\end{tabular}

\section{Experimental}

\section{Materials characterizations}

XRD pattern was collected by a Rigaku X-ray diffractometer with Cu Ka radiation at $30 \mathrm{KV}$ and $15 \mathrm{~mA}$. The SEM images were observed with a HITACHI SU-8230 scanning SEM. TEM images were taken with a JEOL JEM-2100F microscope (operated at $300 \mathrm{kV}$ ). $\mathrm{N}_{2}$ adsorption-desorption, $\mathrm{BJH}$, and BET analyses were carried out at $77 \mathrm{~K}$ using a Microtrac Bel BEL-mini. Prior to the measurements, the samples were evacuated at $90^{\circ} \mathrm{C}$ for $20-24 \mathrm{~h}$. ICP-OES was performed by Pekin-Elmer (USA) model.

\section{Synthesis of Pd@MO-ISO}

For the synthesis of this organosiloxane bridge, 1,3,5-tris(2-hydroxyethyl)-1,3,5-triazinane-2,4,6-trione (THEIC) (3 mmol, $0.783 \mathrm{~g}$ ) was reacted with (3-isocyanatopropyl)triethoxysilane $(1 \mathrm{mmol}, 0.5 \mathrm{~mL})$ at $135^{\circ} \mathrm{C}$ for $3 \mathrm{~h}$ and then, cooled to $80^{\circ} \mathrm{C}$ and stirred at that temperature for another $3 \mathrm{~h}$. Then, a a colorless oily product was obtained at the end which was used without further purifications ${ }^{14}$. The synthesised isocyanurate-based organosiloxane bridge was further employed in the synthesis of the corresponding $\mathrm{MO}$ through co-condensation of TEOS. Accordingly, the pluronic triblock copolymer P123 (2 g, MW = 5800 g. $\left.\mathrm{mol}^{-1}\right)$, was dissolved in $\mathrm{HCl}$ aqueous solution $\left(10^{-4} \mathrm{M}, 75 \mathrm{~mL}\right)$ and stirred for $3 \mathrm{~h}$. Then, the assynthesised organosiloxane bridge from the previous step was mixed with TEOS with the molar ratio of $1: 15$, respectively, and co-condensed in the $\mathrm{P} 123 / \mathrm{HCl}$ aqueous solution mixture and stirred for $24 \mathrm{~h}$ at 25 ${ }^{\circ} \mathrm{C}$. After stirring for $24 \mathrm{~h}$, the reaction mixture was transferred to the autoclave for aging for $24 \mathrm{~h}$ at 100 ${ }^{\circ} \mathrm{C}$. After aging, the polymeric P123 was extracted from the pore space by Soxhlet with $\mathrm{MeOH}$ for 4 days. A white powder as final product after drying at $60^{\circ} \mathrm{C}$ for $4 \mathrm{~h}$ in an oven was obtained. For simplicity, the product obtained in this stage was named MO-ISO. 
Further, MO-ISO was dispersed in acetonitrile and then, $\mathrm{Na}_{2} \mathrm{PdCl}_{4}(39 \mu \mathrm{mol}, 0.0116 \mathrm{~g})$ was added to the mixture under the vigorous stirring. After $4 \mathrm{~h}$, the reaction was stopped, and the creamy product was collected by centrifugation and washing for three times with EtOH $(10 \mathrm{~mL})$. After drying in an oven at $60^{\circ} \mathrm{C}$ for $3 \mathrm{~h}$, it was re-dispersed in $\mathrm{MeOH}$ and then, $\mathrm{NaBH}_{4}$ was added to the dispersion and allowed to stir for $0.5 \mathrm{~h}$. Finally, the final product was centrifuged and washed for three times with ethanol $(10 \mathrm{~mL})$ and dried in oven at $60^{\circ} \mathrm{C}$ for $3 \mathrm{~h}$. For simplicity, the product obtained in this step was named Pd@MOISO. The wt\% of Pd loaded in MO-ISO was analysed by ICP-OES technique, indicating that the Pd content is $0.5 \mathrm{wt} \%$ in the MO-ISO.

\section{General procedure for reduction of p-nitrophenol in the presence of Pd@MO-ISO}

In the catalytic test to reduce $p$-nitrophenol (PNP) into $p$-aminophenol (PAP), Pd@MO-ISO (5 mg) was dispersed in the aqueous PNP solution ( $3 \mathrm{mM}, 40 \mathrm{~mL}$ ) by sonicating for $5 \mathrm{~min}$. Then, the sodium borohydride ( $5 \mathrm{mmol}, 125 \mathrm{mg}$ ) was added to the solution and continued to stir vigorously. During the reaction, every $5 \mathrm{~min}$, the sampling from reaction progress was achieved by a syringe equipped with syringe filter to separate the catalyst from the reaction media. Then, the obtained samples from each minute were analysed by UV-Vis spectrometer to monitor the reaction progress.

\section{Conclusion}

Here, we presented a heterogeneous green catalyst on the basis of a new Pd-based hybrid mesoporous organosilica which could successfully adsorb Pd ions and support it on the surface. The Pd supporting process had not a significant destructive effect on the mesoscopic structure of the MO-ISO and had an efficient catalytic activity in the chemical reduction of PNP to PAP by using $\mathrm{NaBH}_{4}$ as reducing agent. The catalyst also showed a high rate of recyclability and negligible Pd species leaching over the recycling the catalyst. The catalytic activity of Pd@MO-ISO was excellent in comparison to other previously reported catalysts with the similar textural structure.

\section{Declarations}

\section{Acknowledgements}

We are grateful for the financial support from The Research Council of Iran University of Science and Technology (IUST), Tehran, Iran (Grant No 160/19108). We would also like to acknowledge the support of The Iran Nanotechnology Initiative Council (INIC), Iran.

\section{References}

1. Asefa, T., MacLachlan, M. J., Coombs, N. \& Ozin, G. A. Periodic mesoporous organosilicas with organic groups inside the channel walls. Nature. 402, 867-871 (1999). 
2. Inagaki, S., Guan, S., Fukushima, Y., Ohsuna, T. \& Terasaki, O. Novel mesoporous materials with a uniform distribution of organic groups and inorganic oxide in their frameworks. Journal of the American Chemical Society. 121, 9611-9614 (1999).

3. Melde, B. J., Holland, B. T., Blanford, C. F. \& Stein, A. Mesoporous sieves with unified hybrid inorganic/organic frameworks. Chemistry of Materials. 11, 3302-3308 (1999).

4. Doustkhah, E. et al. Organosiloxane tunability in mesoporous organosilica and punctuated Pd nanoparticles growth; theory and experiment. Microporous and Mesoporous Materials. 293, 109832 https://doi.org/10.1016/j.micromeso.2019.109832 (2020).

5. Elhamifar, D., Yari, O. \& Karimi, B. Highly ordered mesoporous organosilica-titania with ionic liquid framework as very efficient nanocatalyst for green oxidation of alcohols. Journal of Colloid and Interface Science. 500, 212-219 https://doi.org/10.1016/j.jcis.2017.04.023 (2017).

6. Mousavi, K. Z. et al. Imidazolium-based mesoporous organosilicas with bridging organic groups for microextraction by packed sorbent of phenoxy acid herbicides, polycyclic aromatic hydrocarbons and chlorophenols. Microchim. Acta. 186, 239 https://doi.org/10.1007/s00604-019-3355-3 (2019).

7. Chandra, D., Das, S. K. \& Bhaumik, A. J. M. \& materials, m. A fluorophore grafted 2D-hexagonal mesoporous organosilica: Excellent ion-exchanger for the removal of heavy metal ions from wastewater. 128,34-40(2010).

8. Kim, Y. \& Lee, J. J. B. \& Bioelectronics. Advanced molecular recognition of 3-nitro-L-tyrosine: The use of zwitterion embedded molecularly imprinted mesoporous organosilica with sub-nanomolar sensitivity.112216(2020).

9. Yamanaka, K., Maegawa, Y., Yamada, Y., Inagaki, S. \& Excited-State Dynamics of 2,2'-Bipyridine Moieties Embedded in the Framework of Periodic Mesoporous Organosilica. The Journal of Physical Chemistry C. 123, 28443-28449 https://doi.org/10.1021/acs.jpcc.9b07546 (2019).

10. Kaczmarek, A. M. et al. Lanthanide-Grafted Bipyridine Periodic Mesoporous Organosilicas (BPyPMOs) for Physiological Range and Wide Temperature Range Luminescence Thermometry. ACS Applied Materials \& Interfaces. 12, 13540-13550 https://doi.org/10.1021/acsami.0c01470 (2020).

11. Etienne, M., Goux, A., Sibottier, E. \& Walcarius, A. J. J. o. n. \& nanotechnology. Oriented mesoporous organosilica films on electrode: a new class of nanomaterials for sensing. 9,2398-2406(2009).

12. Matsukawa, H. et al. Fast and stable vapochromic response induced through nanocrystal formation of a luminescent platinum(II) complex on periodic mesoporous organosilica. Sci. Rep. 9, 15151 https://doi.org/10.1038/s41598-019-51615-w (2019).

13. Wei, Y. et al. Periodic Mesoporous Organosilica Nanocubes with Ultrahigh Surface Areas for Efficient C02 Adsorption. Sci. Rep. 6, 20769 https://doi.org/10.1038/srep20769 (2016).

14. Zebardasti, A., Dekamin, M. G., Doustkhah, E. \& Assadi, M. H. N. Carbamate-Isocyanurate-Bridged Periodic Mesoporous Organosilica for van der Waals CO2 Capture. Inorg. Chem. 59, 11223-11227 https://doi.org/10.1021/acs.inorgchem.0c01449 (2020).

15. Doustkhah, E. \& Ide, Y. Bursting Exfoliation of a Microporous Layered Silicate to Three-Dimensionally Meso-Microporous Nanosheets for Improved Molecular Recognition. ACS Applied Nano Materials. 2, 
7513-7520 https://doi.org/10.1021/acsanm.9b01508 (2019).

16. Hunks, W. J. \& Ozin, G. A. Challenges and advances in the chemistry of periodic mesoporous organosilicas (PMOs). Journal of Materials Chemistry. 15, 3716-3724 https://doi.org/10.1039/B504511H (2005).

17. Doustkhah, E. et al. Merging periodic mesoporous organosilica (PMO) with mesoporous aluminosilica (Al/Si-PMO): A catalyst for green oxidation. Molecular Catalysis. 482, 110676 https://doi.org/10.1016/j.mcat.2019.110676 (2020).

18. Doustkhah, E. et al. Thiourea bridged periodic mesoporous organosilica with ultra-small Pd nanoparticles for coupling reactions. RSC Advances. 7, 56306-56310 https://doi.org/10.1039/C7RA11711F (2017).

19. Doustkhah, E. et al. Efficient $\mathrm{H} 2$ Generation Using Thiourea-based Periodic Mesoporous Organosilica with Pd Nanoparticles. 47,1243-1245, doi:10.1246/cl.180537 (2018).

20. Rostamnia, S., Doustkhah, E., Bulgar, R. \& Zeynizadeh, B. Supported palladium ions inside periodic mesoporous organosilica with ionic liquid framework (Pd@IL-PMO) as an efficient green catalyst for S-arylation coupling. Microporous and Mesoporous Materials. 225, 272-279 https://doi.org/10.1016/j.micromeso.2016.01.014 (2016).

21. Dekamin, M. G., Arefi, E. \& Yaghoubi, A. Isocyanurate-based periodic mesoporous organosilica (PMOICS): a highly efficient and recoverable nanocatalyst for the one-pot synthesis of substituted imidazoles and benzimidazoles. RSC advances. 6, 86982-86988 (2016).

22. Haghighat, M., Shirini, F. \& Golshekan, M. Synthesis of tetrahydrobenzo [b] pyran and Pyrano [2, 3-d] pyrimidinone derivatives using Fe304@Ph-PMO-NaHSO4 as a new magnetically separable nanocatalyst. Journal of nanoscience and nanotechnology. 19, 3447-3458 (2019).

23. Kaczmarek, A. M. \& Van Der Voort, P. Light-Emitting Lanthanide Periodic Mesoporous Organosilica (PMO) Hybrid Materials. Materials. 13, 566 (2020).

24. Yaghoubi, A., Dekamin, M. G. \& Karimi, B. Propylsulfonic acid-anchored isocyanurate-based periodic mesoporous organosilica (PMO-ICS-PrSO $3 \mathrm{H}$ ): A highly efficient and recoverable nanoporous catalyst for the one-pot synthesis of substituted polyhydroquinolines. Catal. Lett. 147, 2656-2663 (2017).

25. Su, L. et al. Site-selective exposure of iron nanoparticles to achieve rapid interface enrichment for heavy metals. Chem. Commun. https://doi.org/10.1039/C9CC09765A (2020).

26. Waki, M., Mizoshita, N., Ohsuna, T., Tani, T. \& Inagaki, S. Crystal-like periodic mesoporous organosilica bearing pyridine units within the framework. Chem. Commun. 46, 8163-8165 https://doi.org/10.1039/C0CC01944E (2010).

27. Zou, H. et al. Amphiphilic hollow porous shell encapsulated Au@Pd bimetal nanoparticles for aerobic oxidation of alcohols in water. Chem. Commun. 51, 14601-14604 https://doi.org/10.1039/C5CC05686A (2015).

28. Mizoshita, N., Tani, T. \& Inagaki, S. Syntheses, properties and applications of periodic mesoporous organosilicas prepared from bridged organosilane precursors. Chem. Soc. Rev. 40, 789-800 (2011). 
29. Attia, M. F., Swasy, M. I., Ateia, M., Alexis, F. \& Whitehead, D. C. Periodic mesoporous organosilica nanomaterials for rapid capture of VOCs. Chem. Commun. 56, 607-610 https://doi.org/10.1039/C9CC09024J (2020).

30. Rostamnia, S. \& Doustkhah, E. Nanoporous silica-supported organocatalyst: a heterogeneous and green hybrid catalyst for organic transformations. RSC Advances. 4, 28238-28248 https://doi.org/10.1039/C4RA03773A (2014).

31. Esquivel, D. et al. Tailoring Bifunctional Periodic Mesoporous Organosilicas for Cooperative Catalysis. ACS Applied Nano Materials. 3, 2373-2382 https://doi.org/10.1021/acsanm.9b02493 (2020).

32. Zarei, M., Zolfigol, M. A., Moosavi-Zare, A. R., Noroozizadeh, E. \& Rostamnia, S. Three-Component Synthesis of Spiropyrans Using SBA-15/En Bonded Phosphorous Acid [SBA-15/Pr-NH1y(CH2PO3H2)y-Et-NH2-x(CH2PO3H2)x] as a New Nanoporous Heterogeneous Catalyst. ChemistrySelect 3, 12144-12149, doi:https://doi.org/10.1002/slct.201802525 (2018).

33. Narani, A., Reddy Kannapu, H. P., Natte, K. \& Burri, D. R. Pd-Nanoparticles immobilized organofunctionalized SBA-15: An efficient heterogeneous catalyst for selective hydrogenation of CC double bonds of a, $\beta$-unsaturated carbonyl compounds. Molecular Catalysis. 497, 111200 https://doi.org/10.1016/j.mcat.2020.111200 (2020).

34. Yu, Y., Li, F., Zang, Z., Xu, L. \& Liu, G. Highly efficient selective oxidation of 2-methylnaphthalene to vitamin K3 over mesoporous Al/Ti-SBA-15 catalysts: The effect of acid sites and textural property. Molecular Catalysis. 495, 111158 https://doi.org/10.1016/j.mcat.2020.111158 (2020).

35. Yang, X., Niu, L., Xia, Z., Yan, X. \& Bai, G. Preparation of Ni/mSiO2 with the existence of hydrogelator: Insight into hydrogelator self-assembly on metal dispersion and catalytic performance in quinoline hydrogenation. Molecular Catalysis. 493, 111094 https://doi.org/10.1016/j.mcat.2020.111094 (2020).

36. Szabó, B. et al. Conversion of ethanol to butadiene over mesoporous In203-promoted MgO-SiO2 catalysts. Molecular Catalysis. 491, 110984 https://doi.org/10.1016/j.mcat.2020.110984 (2020).

37. Shimizu, M., Michikawa, K., Maegawa, Y., Inagaki, S. \& Fujita, K. -i. Iridium Complex Immobilized on Custom-Designed Periodic Mesoporous Organosilica as Reusable Catalyst for the Dehydrogenative Oxidation of Alcohols. ACS Applied Nano Materials. 3, 2527-2535 https://doi.org/10.1021/acsanm.9b02607 (2020).

38. Aalinejad, M., Pesyan, N. N. \& Doustkhah, E. Diaza crown-type macromocycle (kryptofix 22) functionalised carbon nanotube for efficient Ni2 + loading; A unique catalyst for cross-coupling reactions. Molecular Catalysis. 494, 111117 https://doi.org/10.1016/j.mcat.2020.111117 (2020).

39. Rostamnia, S., Doustkhah, E., Karimi, Z., Amini, S. \& Luque, R. Surfactant-Exfoliated Highly Dispersive Pd-Supported Graphene Oxide Nanocomposite as a Catalyst for Aerobic Aqueous Oxidations of Alcohols. ChemCatChem. 7, 1678-1683 https://doi.org/10.1002/cctc.201500126 (2015).

40. Esmat, M. et al. 2D Mesoporous Channels of PMO; a Platform for Cluster-Like Pt Synthesis and Catalytic Activity in Nitrophenol Reduction. 10,167(2020). 
41. Shokouhimehr, M. et al. Magnetically retrievable nanocomposite adorned with Pd nanocatalysts: efficient reduction of nitroaromatics in aqueous media. Green Chem. 20, 3809-3817 https://doi.org/10.1039/C8GC01240G (2018).

42. Doustkhah, E., Hasani, M., Ide, Y. \& Assadi, M. H. N. Pd Nanoalloys for H2 Generation from Formic Acid. ACS Applied Nano Materials. 3, 22-43 https://doi.org/10.1021/acsanm.9b02004 (2020).

43. Sangili, A., Annalakshmi, M., Chen, S. M., Balasubramanian, P. \& Sundrarajan, M. Synthesis of silver nanoparticles decorated on core-shell structured tannic acid-coated iron oxide nanospheres for excellent electrochemical detection and efficient catalytic reduction of hazardous 4-nitrophenol. Composites Part B: Engineering. 162, 33-42 https://doi.org/10.1016/j.compositesb.2018.10.084 (2019).

44. Berillo, D. \& Cundy, A. 3D-macroporous chitosan-based scaffolds with in situ formed Pd and Pt nanoparticles for nitrophenol reduction. Carbohydrate polymers. 192, 166-175 (2018).

\section{Figures}

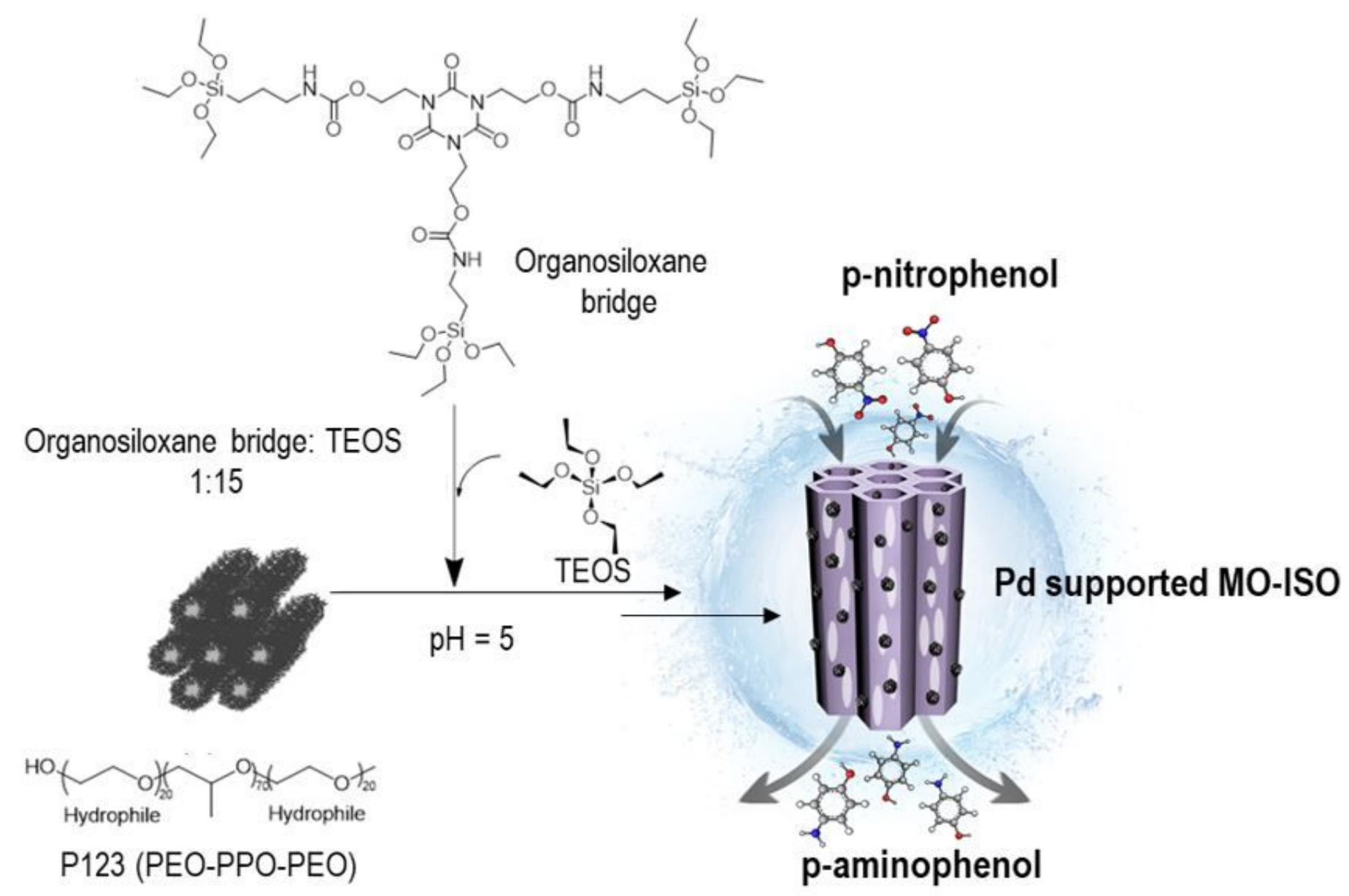

Figure 1

Schematic representation of Pd@MO-ISO synthesis. 

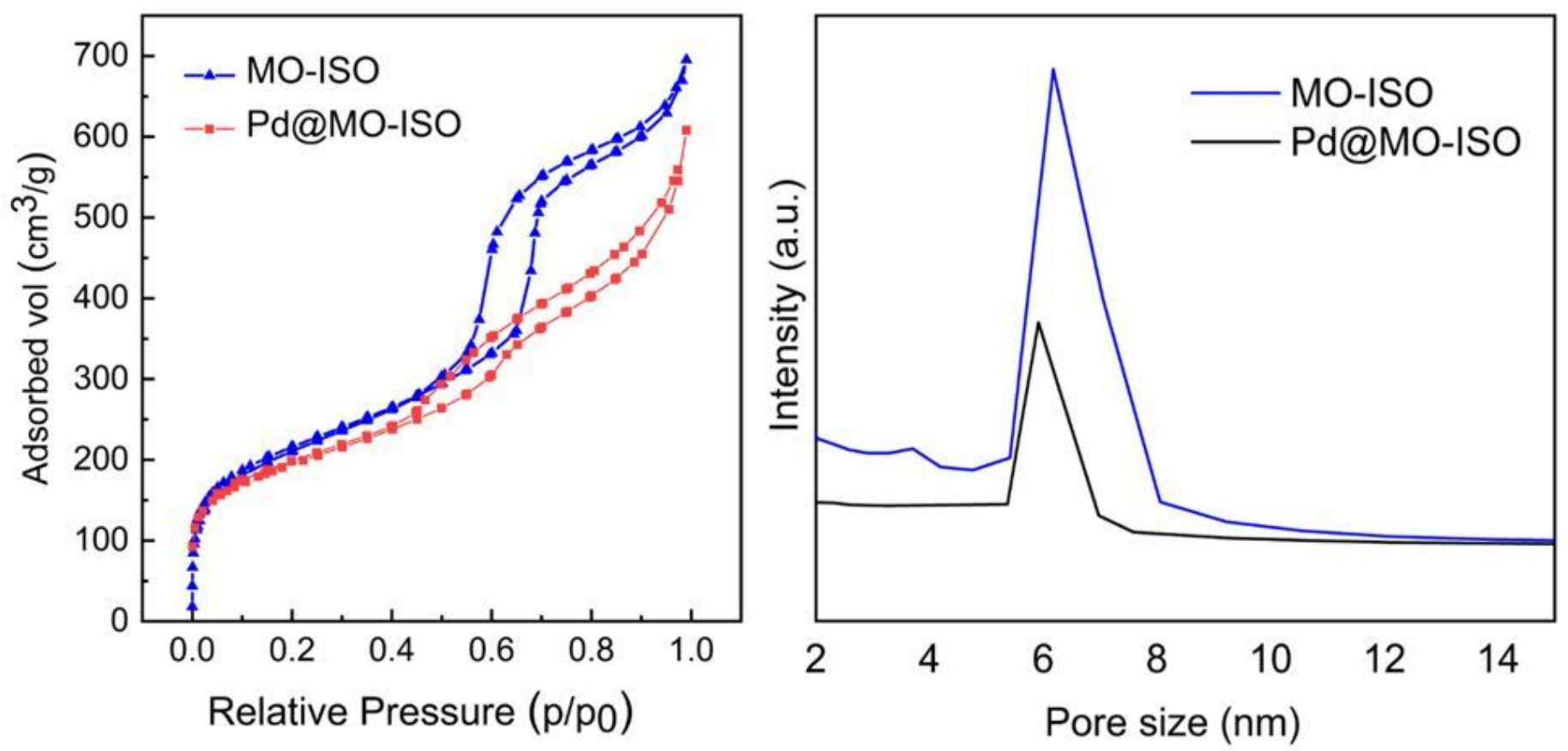

Figure 2

a) N2 adsorption-desorption isotherms and b) BJH plots of MO-ISO and Pd@MO-ISO. 


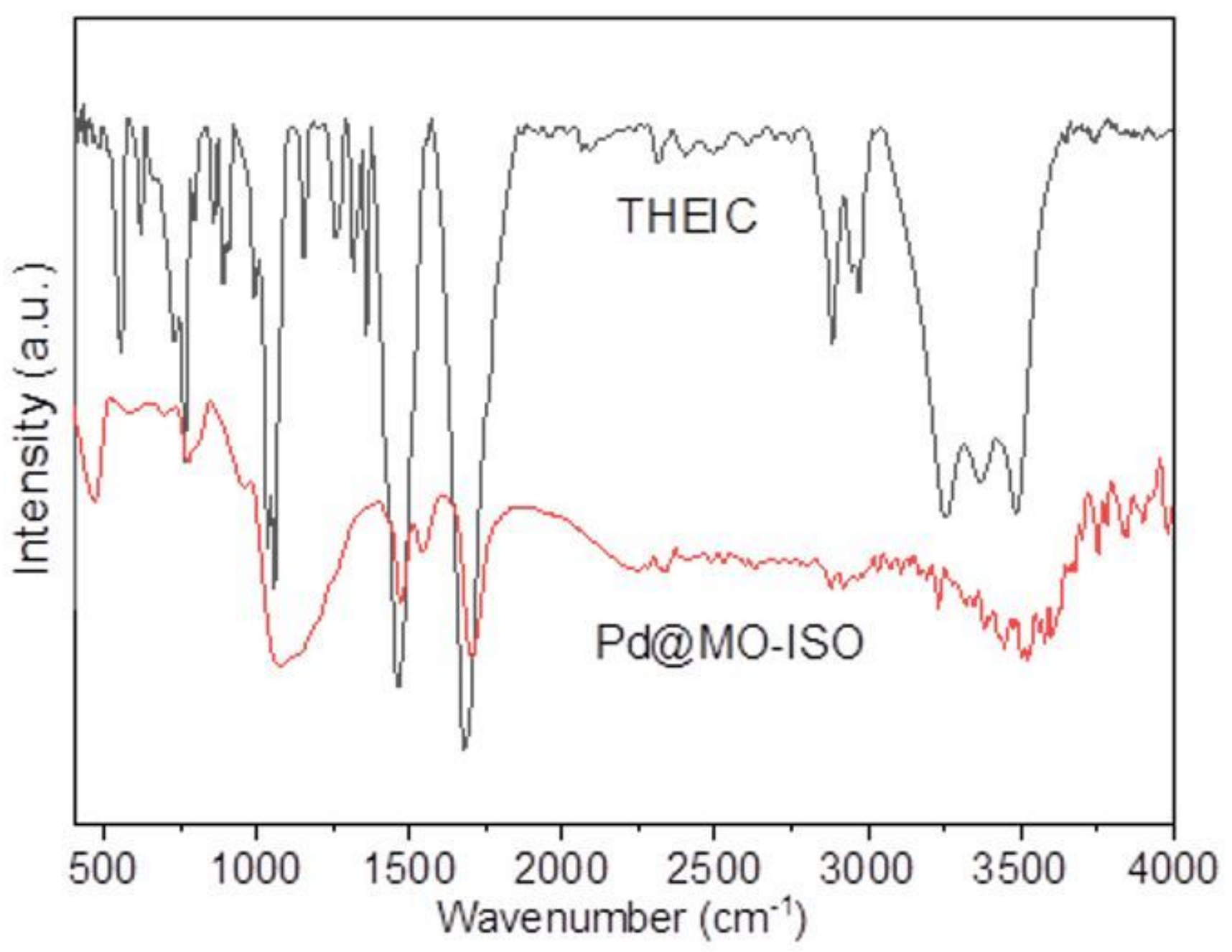

Figure 3

ATR-FTIR spectra of THEIC and Pd@MO-ISO. 


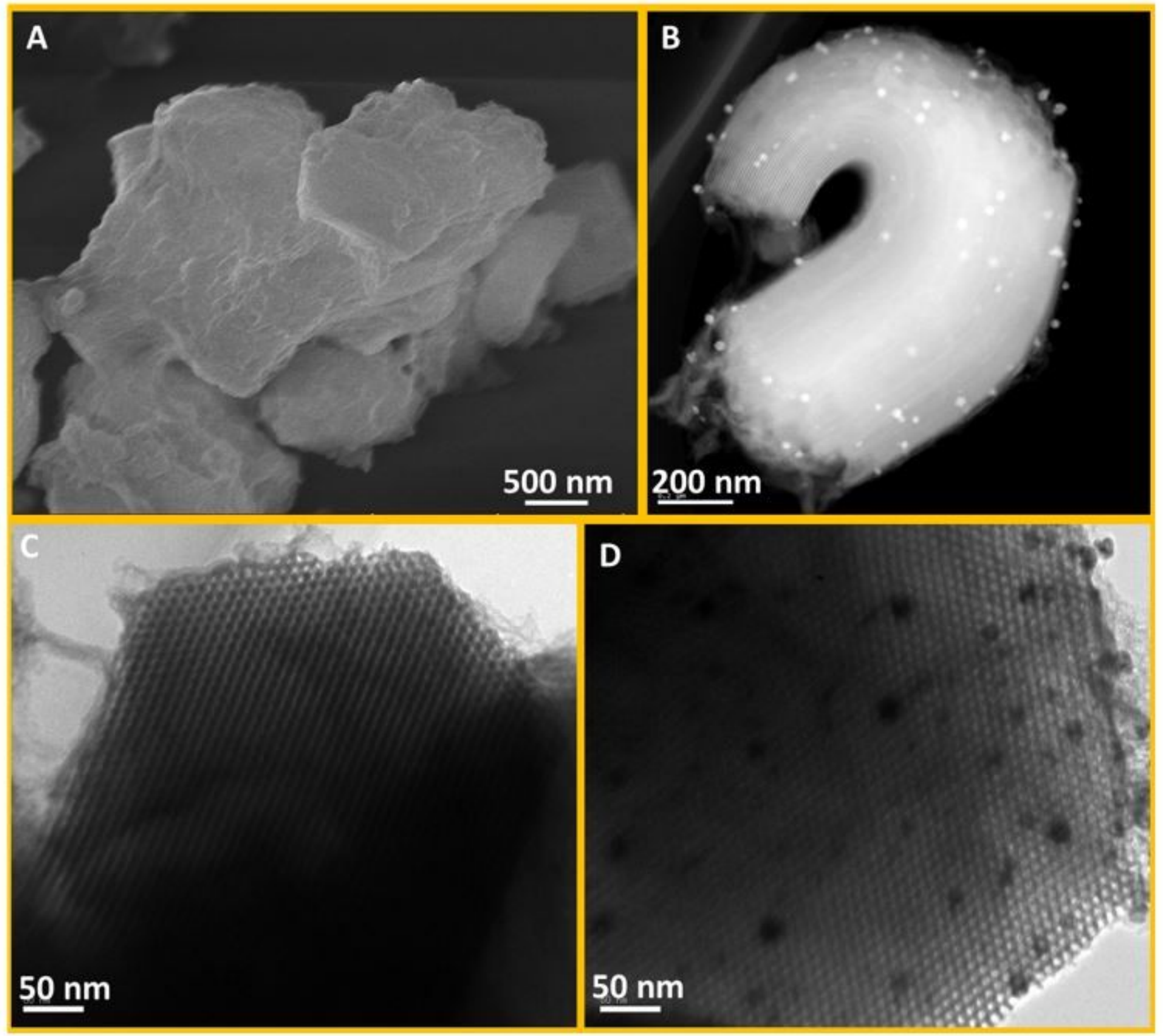

Figure 4

A) SEM and B) HAADF-STEM images of Pd@MO-ISO. TEM images of c) MO-ISO and d) Pd@MO-ISO. 

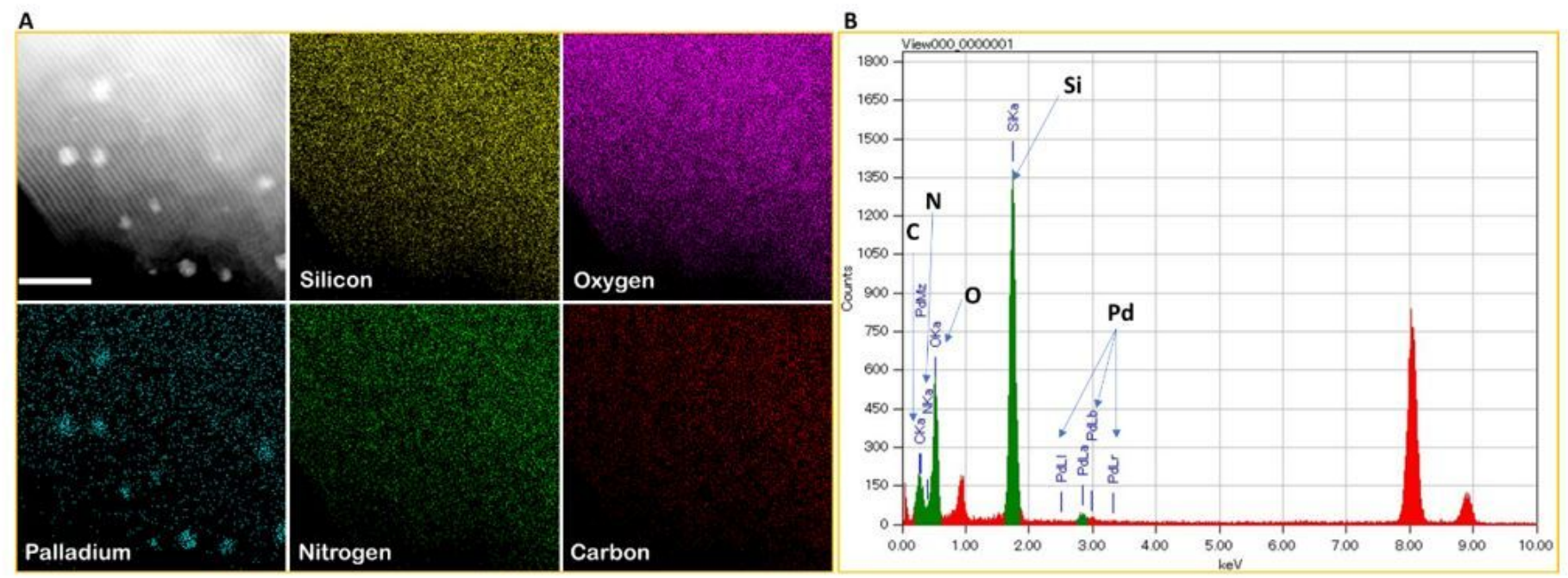

\section{Figure 5}

A) HAADF-STEM image and elemental TEM-mapping images of every element in a separate image related to Pd@MO-ISO. Scale bar shows 100 nm and is constant for all images. B) TEM-EDS spectra of Pd@MO-ISO. 


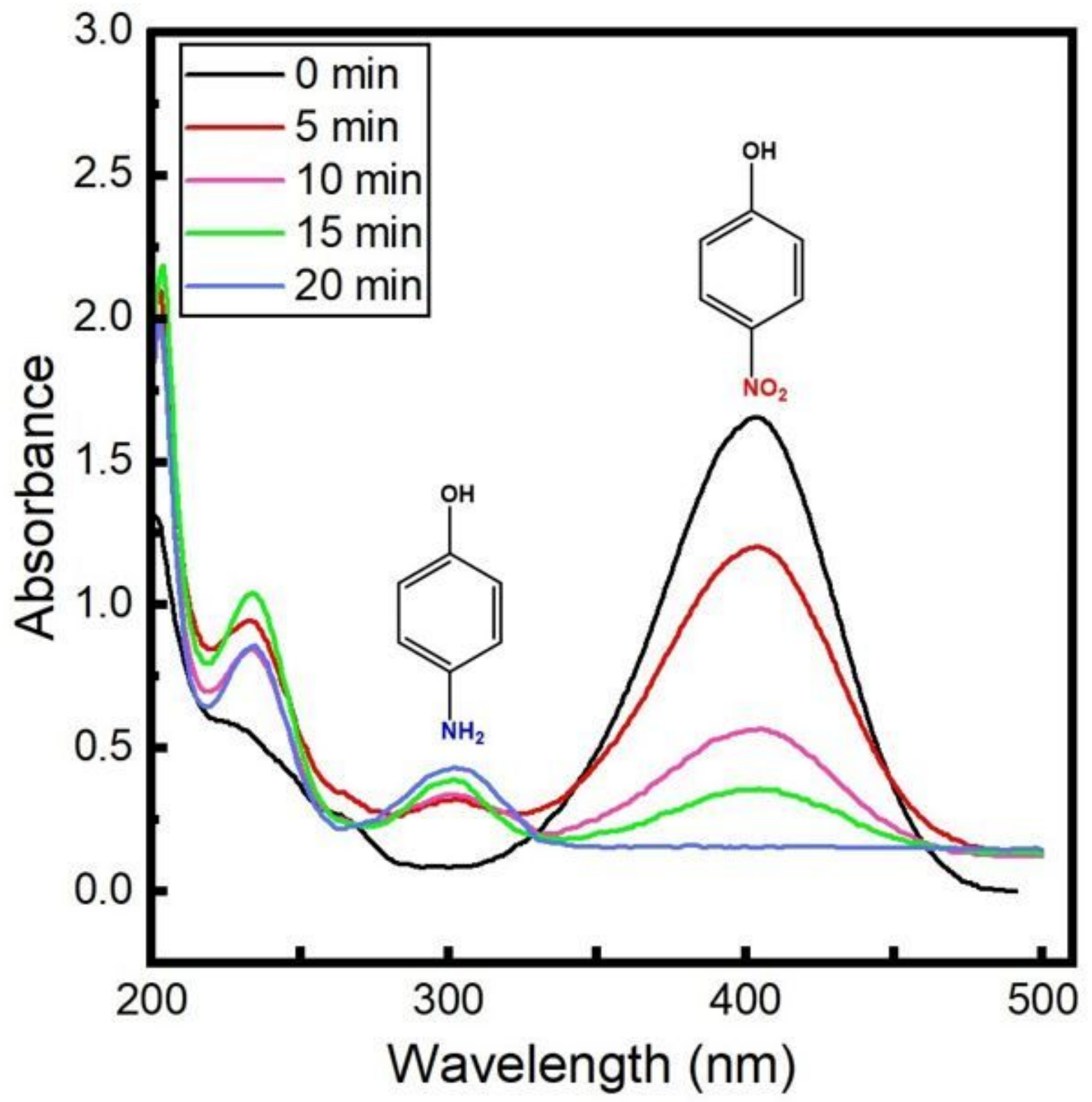

Figure 6

Scanning the UV-Visible spectra of PNP solution catalytically reduces to PAP. 

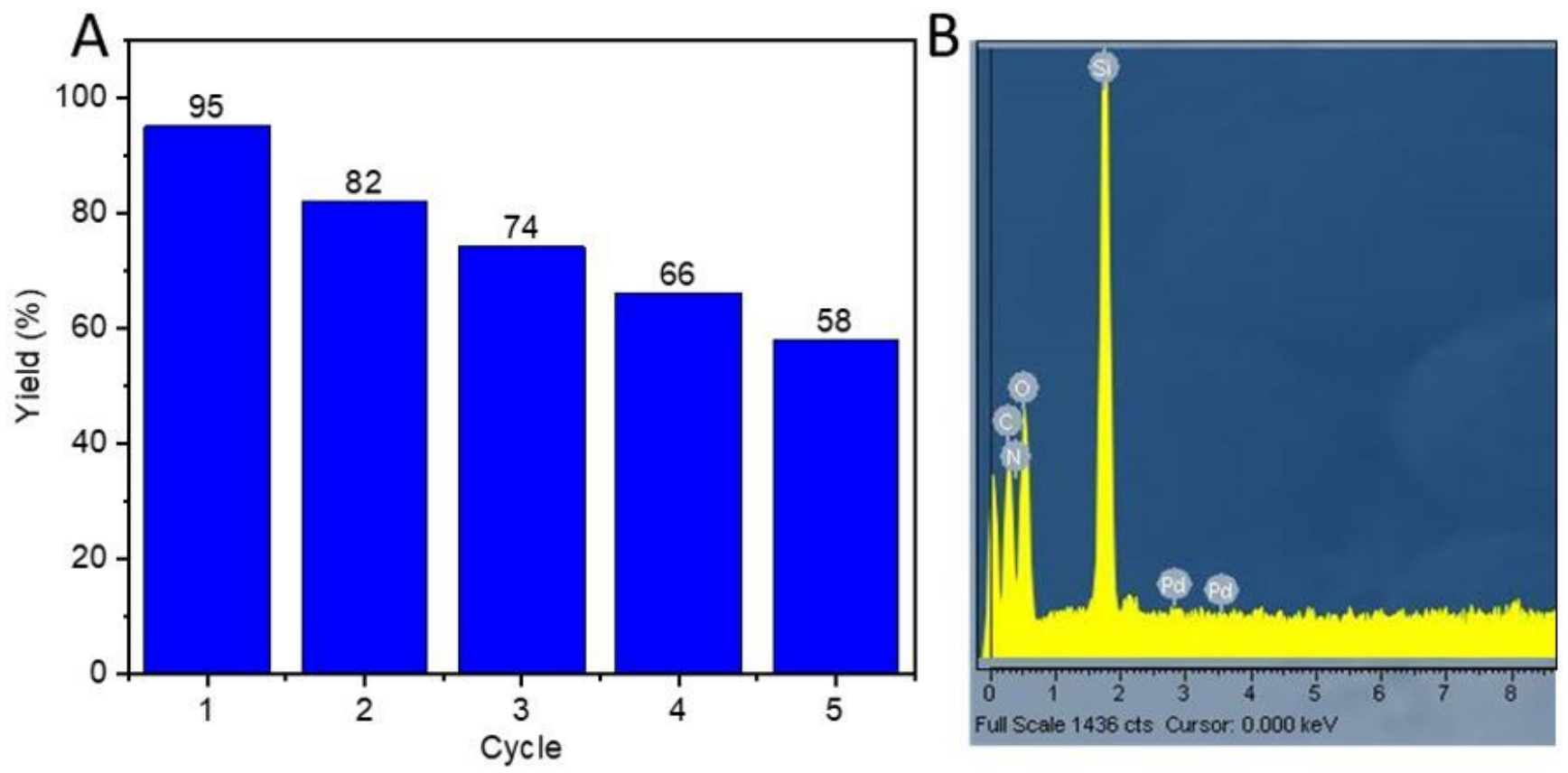

Figure 7

A) Recyclability of the Pd@MO-ISO as catalyst in the reduction of PNP into PAP in five consecutive cycles. B) EDS spectra of PD@MO-ISO after five consecutive catalytic cycles. 